\title{
TERRITÓRIOS DE MORTE: VISIBILIDADE DOS JOVENS RESIDENTES EM PORTO ALEGRE VÍTIMAS DE HOMICÍDIO NOS ANOS DE 2015, 2016 E 2017
}

\author{
Betina Warmling Barros ${ }^{1}$ \\ Ana Paula Motta Costa ${ }^{2}$ \\ Giovanna da Silva Araujo 3 \\ Victória Hoff da Cunha ${ }^{4}$
}

\section{RESUMO}

Trata-se de pesquisa que visa mapear os homicídios que vitimizam sujeitos residentes em Porto Alegre entre os anos 2015 e 2017, identificando suas principais características, bem como os bairros em que residiam e os locais de ocorrência das mortes. A partir dos dados do Sistema de Informação

\footnotetext{
${ }^{1}$ Mestranda em Sociologia na UFRGS. Bolsista de Mestrado CNPQ. Graduada em Ciências Jurídicas e Sociais pela UFRGS (2017). Foi Bolsista de Iniciação Científica CNPQ (2017). Possui experiência na área da justiça juvenil e sociologia da violência. Instituição: Universidade Federal do Rio Grande do Sul. Brasil. E-mail: barros.betina3@gmail.com

${ }^{2}$ Graduada em Direito pela PUC/RS (2000), Advogada, Bacharel em Ciências Sociais pela UNISINOS (1990). Pósgraduada em Educação pela UFRGS (1992), Mestre em Ciências Criminais pela PUC/RS (2004) e Doutora em Direito pela PUC/RS (2011), tendo realizado estágio doutoral na Universidade Pablo de Olavide, na Espanha, no ano de 2009. Sua tese, aprovada com louvor, recebeu menção honrosa no prêmio CAPES 2011. É Professora da Faculdade de Direito da Universidade Federal do Rio Grande do Sul - UFRGS, onde está vinculada ao Departamento de Ciências Criminais, ministra disciplinas de Direito Penal e Criminologia; coordena Projeto de Pesquisa inscrito no CNPQ e Projetos de Extensão Universitária. É Professora do programa de Pós-graduação Mestrado do Centro Universitário RItter dos Reis - UNIRITTER - Mestrado em Direitos Humanos. Foi Pesquisadora do "Projeto Pensando o Direito", desenvolvido pelo Ministério da Justiça e IPEA. Foi Professora do Programa de Pós-graduação em Direito - Mestrado da Fundação Meridional - IMED, em Passo Fundo/RS. Foi Coordenadora do Curso e Coordenadora do Núcleo de Prática Jurídica do Curso de Direito do Centro Universitário Metodista do IPA. Como convidada, ministra aulas em Cursos de Especialização em Direito da Criança e do Adolescente da FMP/RS. Tem experiência na área de Direito, com ênfase em Direito da Criança e do Adolescente, atuando principalmente nos seguintes temas: adolescência, infância, Estatuto da Criança e do Adolescente, medidas socioeducativas. Realizou consultorias em Projetos Sociais, em especial junto à UNESCO, PNUD e Ministério do Desenvolvimento Social - MDS. Foi presidente da Fundação de Assistência Social e Cidadania da Prefeitura de Porto Alegre (1997-2000 e 2003-2004), e presidente da Fundação de Atendimento Socioeducativo do RGS (FASE/RS) de 2000-2002. É autora dos livros: "As garantias Processuais e o Direito Penal Juvenil" (2005) e "Os Adolescentes e seus Direitos Fundamentais" (2011), ambos publicados pela Livraria do Advogado Editora; e ainda do livro "Medidas Socioeducativas - Gestão da Execução" (2014), editado pela MarcaVisual Editora. Instituição: Faculdade de Direito da UFRGS e Mestrado em Direito UniRitter. Brasil. Email: anapaulamottacosta@gmail.com

${ }^{3}$ Acadêmica do curso de Ciências Jurídicas e Sociais da UFRGS. Integrante do Observatório de Pesquisa Violência e Juventude. Integrou o Serviço de Assessoria Jurídica Universitária - SAJU/UFRGS como assistente jurídica, fazendo parte do grupo G11 - Adolescentes em situação de conflito com a lei (2016/2 - 2018/1). Instituição: Universidade Federal do Rio Grande do Sul. Brasil. E-mail: gsaraujos@gmail.com

${ }^{4}$ Acadêmica em Ciências Jurídicas e Sociais da Universidade Federal do Rio Grande do Sul (UFRGS). Integrou o Serviço de Assessoria Jurídica Universitária (SAJU - UFRGS), enquanto assistente jurídica do Grupo de Assessoria Popular (GAP). É bolsista de iniciação Científica (FAPERGS) sob orientação da Profa . Ana Paula Motta Costa no Observatório de Pesquisa em Violência e Juventude. Instituição: Universidade Federal do Rio Grande do Sul. Brasil. E-mail:vhcunha95@gmail.com
} 
sobre Mortalidade (SIM) fornecidos pela Secretaria Municipal de Saúde, optou-se pela análise do perfil das vítimas em relação à faixa etária, ao sexo e à raça. Após, com a utilização do software QGis, buscou-se mapear os locais de vida e morte dos jovens assassinados, com idades entre 15 e 29 anos. Assim, foi possível reafirmar a ideia de que os homicídios vitimizam principalmente jovens negros do sexo masculino. Entretanto, a curva da faixa etária apresentou um pico de vítimas que possuem entre 15 e 19 anos, o que não era uma realidade uma década atrás. Ademais, notou-se a diminuição proporcional de vítimas brancas, bem como uma maior representativa de mulheres. Por fim, tanto em relação aos locais de vida como de morte, ao mesmo tempo que se observa uma forte concentração nos bairros Rubem Berta, Restinga, Santa Tereza, Sarandi e Lomba do Pinheiro, também foi possível verificar uma crescente difusão territorial dos homicídios.

Palavras-chave: juventude; homicídios; violência; mapas; território.

ABSTRACT: The paper aims to map the homicides that victimize individuals residing in Porto Alegre between the years 2015 and 2017, identifying their main characteristics, as well as the neighborhoods where they lived and the deaths places. Based on data from the Mortality Information System (SIM) provided by the Municipal Health Department, we chose to analyze the profile of the victims in relation to age, gender and race. It was used the QGis software to map the life and death sites of the murdered youth, aged between 15 and 29 years. Thus, it was possible to reaffirm the idea that homicides mainly victimize young black males. However, the age curve showed a peak of victims between 15 and 19 years old, which was not a reality a decade ago. In addition, it was noted the proportional decrease of white victims, as well as a greater women representation. Finally, in relation to life and death places, while there is a strong concentration in the neighborhoods Rubem Berta, Restinga, Santa Tereza, Sarandi and Lomba do Pinheiro, it was also possible to verify a growing territorial homicides spread.

Key-words: youth; homicide; violence; maps; territory.

\section{INTRODUÇÃO}

"Porto Alegre é listada entre as cidades mais violentas do mundo" é a manchete do jornal de maior circulação no Rio Grande do Sul no dia 02 de abril de $2017^{1}$. A reportagem apresenta os dados de pesquisa realizada pelo Instituto Igarapé e publicado no jornal The Economist. Desde o final do ano de 2016 e durante todo o ano de 2017, diversas notícias dão conta de um cenário de aumento vertiginoso dos episódios de violência letal na capital gaúcha, com casos emblemáticos que inclusive chegam a provocar mudanças na administração da cidade, por exemplo, com o início da atuação da 
Força Nacional em auxílio à Polícia Militar a partir de agosto de 2016 e ainda sem previsão de encerramento das atividades.

Ainda existem muitas lacunas na compreensão do fenômeno do aumento da mortalidade violenta na cidade. Em que pese a existência de iniciativas importantes, como a plataforma eletrônica "Raio-X da Violência" realizada pelo Grupo RBS, carecem pesquisas que possibilitem compreender quem são os indivíduos mais afetados pela crescente no número de homicídios, e sobretudo qual a sua distribuição no território da cidade. Assim, o presente artigo traça algumas primeiras considerações a respeito dessas questões, na medida em que pretende construir o perfil dos moradores de Porto Alegre que foram vítimas de homicídios, identificando os bairros em que residiam e o local em que os eventos homicidas ocorreram nos anos de 2015, 2016 e 2017.

É importante frisar que a pesquisa se diferencia da grande parte das pesquisas sobre homicídios, na medida em que busca averiguar quem são, onde vivem e onde morreram os jovens vítimas de homicídio residentes em Porto Alegre. Assim, o recorte maior realizado diz respeito aos jovens residentes na cidade vítimas deste tipo de mortalidade violenta, não importando onde o evento homicida tenha ocorrido. Conforme se verá, a grande maioria dos eventos também ocorreu em Porto Alegre, mas há casos em que jovens moradores da cidade foram mortos em outros municípios.

Justifica-se a escolha por esse recorte, na medida em que não foram identificadas pesquisas anteriores preocupadas em avaliar o perfil das vítimas de homicídio oriundas de Porto Alegre, mas somente investigações com referência aos eventos violentos ocorridos na cidade. Não se sabia, portanto, se os moradores da cidade, identificados social e culturalmente com o local, foram vítimas deste tipo de letalidade violenta também na circunscrição geográfica do município ou se os eventos violentos extrapolavam esses limites territoriais. Assim, pode se dizer que a grande inovação da presente pesquisa diz respeito à tentativa de avaliar a correspondência entre localidade de residência e localidade de morte dos jovens, identificando em que medida os moradores de Porto Alegre são assassinados na própria cidade ou em localidades diversas, bem como a distribuição espacial destas ocorrências.

Em relação ao perfil das vítimas, a hipótese que guia a presente pesquisa entende que os homens jovens representam a maioria das vítimas deste tipo de morte violenta, além da existência de um fator racial que aumenta a proporção de negros no total dos homicídios em comparação com a distribuição racial da população da cidade. Em relação às localidades, também se acredita que um número restrito de bairros de Porto Alegre são identificados como locais de morte da grande maioria dos homicídios dos jovens que residem de cidade. 
Para dar cabo ao proposto, a pesquisa utilizou dados coletados e organizados pelo Sistema de Informação sobre Mortalidade (SIM), vinculado à Secretaria de Saúde da cidade de Porto Alegre (SMSPA). Para ter acesso às informações, a pesquisa tramitou pelo período de oito meses no Comitê de Ética e Pesquisa da UFRGS (CEP-UFRGS) e no Comitê de Ética da SMSPA. A primeira submissão do projeto ao CEP-UFRGS foi no dia 14/07/2017 e o parecer de aprovação foi liberado no dia 14/09/2017. Após a aprovação no comitê da universidade, neste mesmo dia, foi feita a inclusão do Comitê da SMSPA como instituição coparticipante, com parecer liberado no dia 22/02/2018. Assim, foi conferido às pesquisadoras o acesso aos dados brutos do SIM que servem como a principal fonte do presente artigo e que foram trabalhados da forma que se expõe a seguir.

\section{METODOLOGIA}

Com o intuito de melhor estabelecer o panorama recente dos homicídios de jovens na cidade de Porto Alegre, sobretudo sua localização no território da cidade e o perfil mais detalhado de suas vítimas, buscou-se os dados primários através do Sistema de Informação sobre Mortalidade (SIM). A fonte utilizada, portanto, é aquela de diversos estudos na área da violência, na medida em que são dados primários disponíveis em todo o país e com procedimentos de catalogação padronizados (PROVENZA, et al, 2017, p. 300). A análise do banco de dados foi realizada através do programa IBM SPSS (Statistical Package for the Social Sciences ${ }^{2}$ ).

Os dados brutos do ano de 2015, que incluem todos os óbitos ocorridos com moradores de Porto Alegre, representam um total de 11454 óbitos, de causas naturais ou não naturais. A partir do Dicionário de Dados do SIM foi possível realizar a identificação das variáveis e de seus valores. A variável CIRCOBITO, do banco de dados do SIM, indica qual foi a provável circunstância de morte não natural, separando esses tipos de violência em cinco valores: acidente; suicídio; homicídio; outros e ignorado. Realizou-se a seleção das mortes que ocorrem por homicídios, gerando um novo banco de dados totalizando 678 homicídios. Já no ano de 2016, o número total de óbitos era de 12556, incluindo causas naturais ou não. Realizada a seleção de homicídios chegou-se ao total de 803 vítimas. Em 2017, o número total de óbitos chegou em 11.971, sendo que 661 destes foram classificados como homicídios.

Posteriormente o banco de dados foi dividido a partir de três critérios: faixa etária, sexo e identificação como brancos ou não-brancos. A última etapa da pesquisa, então, consistiu na análise do local de vivência e de morte dos jovens que residiam em Porto Alegre durante os anos de 2015, 2016 e 2017, a partir da construção de representações cartográficas indicando tal distribuição territorial. Antes de adentrar nos resultados das análises realizadas, importa retomar os dados 
apresentados em outras pesquisas somente no que se refere aos homicídios ocorridos na capital gaúcha.

Nesse sentido, a ideia de realizar um mapa dos homicídios da cidade não é inédita e também foi objetivo da relevante pesquisa publicada no ano de 2010, na qual se realizou uma Cartografia Social dos Homicídios em Porto Alegre no período de 2002 a 2006 (RUSSO; SANTOS, 2010). Como já haviam demonstrando alguns estudos sobre o perfil da vítima da letalidade violenta no Brasil ser aquele de homens, jovens, negros, moradores de áreas carentes (MINAYO \& SOUZA, 2003; LEMGRUBER, 2006), Santos e Russo ratificam essa conclusão no que diz respeito à capital gaúcha (2010, p. 213). Segundo os autores, em 2006, a cidade possuía uma taxa de 30,9 homicídios por 100 mil habitantes, representando a sétima maior taxa de óbito, dois pontos percentuais abaixo da média nacional (RUSSO; SANTOS, 2010, p. 214).

Em estudo específico sobre homicídios e juventude no Brasil publicado no ano de 2013, demonstrou-se que a cidade de Porto Alegre, no período compreendido entre os anos 2001 e 2011, mantinha sua taxa de homicídio do total da população em um certo padrão, atingindo a taxa mínima no ano de 2006 (35,5 homicídios para 100 mil habitantes) e a máxima de 47,3 no ano de 2007 (WAISELFISZ, 2013, p. 48). A taxa de variação do período foi de apenas 1,3\%. Entretanto, no que se refere à taxa de homicídios específica da população jovem, a variação chegou a 18,3\% no mesmo período, com uma taxa de 114,4 homicídios para 100 mil habitantes no ano de 2007 (ibidem, p. 57)

Em relação ao panorama mais recente, nota-se que os dados publicados no ano de 2018 pelo Anuário de Segurança Pública (FBSP, 2018) mostram que na cidade de Porto Alegre em 2015 foram cometidos 744 homicídios. Assim, chega-se, no mesmo ano, à taxa de 52,9 Crimes Violentos Letais Intencionais ${ }^{3}$ a cada 100 mil habitantes. Já em 2016, há uma divergência importante. Em uma primeira publicação, os homicídios dolosos da capital gaúcha somam, no ano de 2016, um total de 908 vítimas (FBSP, 2017). Na publicação do ano seguinte, há uma revisão dos dados que acaba diminuindo esse montante para 785 (FBSP, 2018).

Por fim, em 2017, os dados apontam a ocorrência de 660 homicídios dolosos, representando a taxa de 45,6 Mortes Violentas Intencionais ${ }^{4}$ por 100 mil habitantes (FBSP, 2018). É válido considerar que a fonte dos dados de tal publicação são as Secretarias Estaduais de Segurança Pública e/ou Defesa Social, o Instituto Brasileiro de Geografia e Estatística (IBGE) e o Fórum Brasileiro de Segurança Pública, e não o Sistema de Informações sobre Mortalidade, fonte utilizada pelo Mapa da Violência 2013 (WAISELFISZ, 2013, p. 15).

Assim, apenas pela análise primeira de tais dados secundários, nota-se um importante acréscimo nos homicídios na cidade de Porto Alegre na última década de forma bastante acentuada, sobretudo em comparação com outras importantes capitais do país, como o Rio de Janeiro. Na 
cidade, conhecida pelo senso comum como local com altos índices de letalidade violenta, averiguouse uma taxa de 42,3 homicídios/100 mil habitantes no ano de 2006, isto é, bem acima dos 30,9 da capital gaúcha à época. Entretanto, segundo o FBSP, no ano de 2015, a taxa referente às Mortes Violentas Intencionais da capital carioca foi de 19,4 em 2015, 30,0 em 2016 e 32,7 em 2017 (FBSB, 2017;2018). Já Porto Alegre apresentou taxas de 52,9, 55,8 e 45,6, nos respectivos anos (FBSB, 2017;2018).

Tendo em vista que os dados que serão apresentados e debatidos no presente trabalho são oriundos do SIM, a presente pesquisa identificou algumas distorções em relação aos dados publicados pelo Anuário de Segurança Pública. Assim, de acordo com o SIM, em 2015 o número absoluto de homicídios ocorridos na cidade de Porto Alegre foi de 625, enquanto que em 2016 esse valor chegou a 746 vítimas, e em 2017 tal valor foi de 601 vítimas de homicídio no município. Em relação às taxas de homicídio para 100 mil habitantes, utilizou-se as Estimativas Populacionais fornecidas pela Fundação de Economia e Estatística (FEE, 2015;2016;2017), o que levou às seguintes taxas:

Tabela 1: Homicídios por 100 mil habitantes

\begin{tabular}{|l|l|l|l|}
\hline & $\begin{array}{l}\text { Homicídios em Porto } \\
\text { Alegre (SIM) }\end{array}$ & População (FEE) & Taxa por 100 mil habitantes \\
\hline 2015 & 625 & 1.465 .428 & 42,6 homicídios/100mil habitantes \\
\hline 2016 & 746 & 1.464 .231 & 50,9 homicídios/100mil habitantes \\
\hline 2017 & 601 & 1.468 .301 & 40,9 homicídios/100mil habitantes \\
\hline
\end{tabular}

Conforme já exposto, o objetivo da presente pesquisa busca traçar o perfil dos jovens vítimas de homicídio residentes em Porto Alegre o que é ligeiramente distinto das análises retomadas até o momento, as quais buscavam identificar os homicídios ocorridos no território da cidade (sem qualquer identificação sobre os locais de residência desses sujeitos). Assim, os próximos tópicos baseiam suas análises a partir do número total de homicídios ocorridos com os jovens residentes em Porto Alegre, o que é superior aos valores identificados na tabela acima, uma vez que existem eventos ocorridos em outras cidades, conforme será abordado no tópico 3.3.

\section{ANÁLISE DOS DADOS}


3.1 Parâmetros de análise (2015-2016)

\subsubsection{Idade:}

O primeiro parâmetro de análise realizado pela pesquisa diz respeito à idade das vítimas de homicídio entre os anos 2015 e 2017 moradores da cidade de Porto Alegre. Limitando-se à faixa etária que corresponde ao conceito legal de juventude, conforme dispõe o Estatuto da Juventude (Lei 12.852 de 2013) em seu art. $1^{\circ}, \S 1^{\circ}$, realizou-se um primeiro recorte a fim de melhor se averiguar como se distribuíam as mortes por homicídio entre aqueles que possuíam entre 15 e 29 anos de idade. A opção por essa faixa etária, para além do respeito à definição legal, operou-se a partir de uma compreensão que pretende amplificar ao máximo a ideia de juventude, compreendendo o início da adolescência e estendendo a análise até quase o início da adultez.

Assim, de um número total de 678 homicídios no ano de 2015, 351 estão compreendidos nesta faixa etária, o que representa em torno de 51,80\% do número total de mortes. Já no ano de 2016, a representação da juventude na totalidade de homicídios aumenta para 58,0\%, sendo 466 jovens de um total de 803 indivíduos vítimas de homicídio. Por fim, em 2017 de um total de 666 homicídios, 361 são jovens, representando 54,6\% do número total de mortes.

Gráfico 1: Homicídios de jovens residentes em Porto Alegre nos anos de 2015, 2016 e 2017

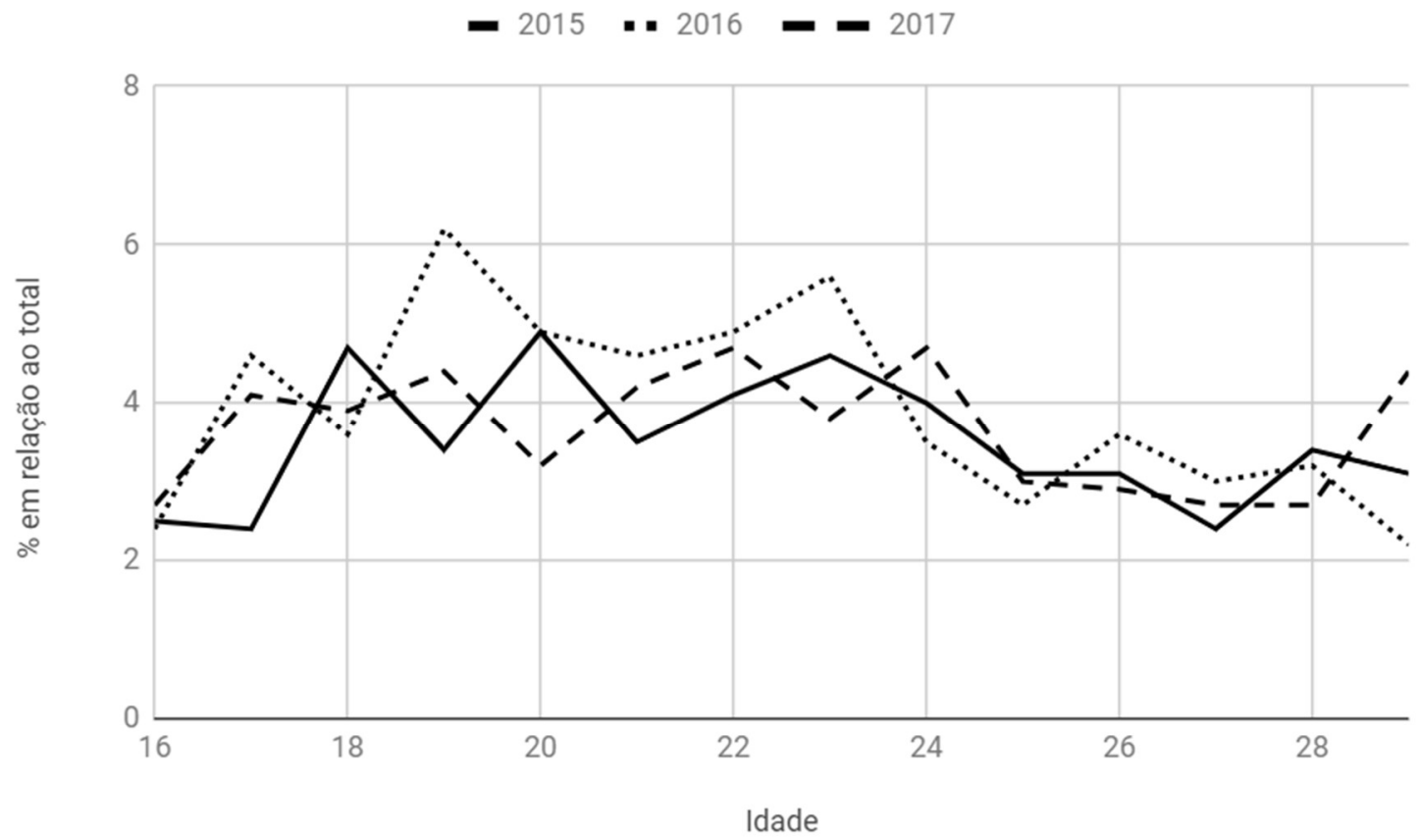

Fonte: SIM/Secretaria de Saúde de Porto Alegre; elaboração própria. 
Conforme percebe-se do gráfico acima, além do aumento da proporção de jovens em relação à totalidade de homicídios, há duas idades em que o aumento de um ano para outro é substancial. Assim, nas idades de 16 e 18 anos, houve um aumento de mais de 20 homicídios de um ano para o outro, crescimento que se verificou em quase todas as faixas etárias, com exceção das idades de 14, 17 e 28 anos. No ano de 2015 a faixa etária crítica dentro do recorte da juventude manteve-se entre os 17 e os 21 anos; já em 2016, há um deslocamento "para trás", isso é, o período crítico inicia aos 16 e se estende até os 21 anos. Nesse ano, há também um segundo intervalo problemático de aumento dos homicídios, entre os 25 e 27 anos. Por fim, em 2017, os picos de homicídio são aos 21, 23 e 28 anos, com uma queda importante na faixa etária entre os 24 e 26 anos. Nas demais idades, identifica-se uma alternância em aumentos e quedas a cada ano, sem que possa se identificar um padrão nessas ocorrências.

Para realizar uma comparação temporal, utilizou-se os dados apresentados na pesquisa de Santos e Russo (2010) em paralelo com o recorte de idade dos jovens residentes e mortos na cidade de Porto Alegre ${ }^{5}$. Nota-se que a representação da juventude no número total de mortes violentas na cidade de Porto Alegre parece ser, no período recente, mais importante do que fora constatado no ano de 2006, quando a maior porcentagem de vítimas de homicídios concentrava-se na faixa etária entre 25 a 34 anos (28,7\%), seguido da faixa entre 35 a 49 (24,6\%) (RUSSO; SANTOS, 2010, p. 219). Assim, os homicídios entre 15 e 24 anos, à época, representavam 34\% do total de vítimas. Dez anos depois, a mesma faixa etária corresponde a $43,1 \%$ do número total:

Tabela 2: Faixa etária das vítimas de homicídio de Porto Alegre (2006, 2015, 2016 e 2017)

\begin{tabular}{|c|c|c|c|c|}
\hline \multirow[t]{2}{*}{ Faixa etária } & \multicolumn{3}{|l|}{$\begin{array}{l}\% \text { do total de } \\
\text { homicídios em Porto } \\
\text { Alegre }\end{array}$} & \\
\hline & $2006^{*}$ & 2015 & 2016 & 2017 \\
\hline Até 14 anos & 1,8 & 2,7 & 1,7 & 0,8 \\
\hline 15 a 19 anos & 12,5 & 18,7 & 21,9 & 18,1 \\
\hline 20 a 24 anos & 21,5 & 19,2 & 21,2 & 19,5 \\
\hline 25 a 34 anos & 28,7 & 29,6 & 26,8 & 29,5 \\
\hline
\end{tabular}




\begin{tabular}{|l|l|l|l|l|}
\hline 35 a 49 anos & 24,6 & 20,3 & 18,2 & 23,8 \\
\hline 50 a 59 anos & 6,2 & 5,6 & 5,2 & 3,9 \\
\hline Mais de 60 anos & 3,9 & 3,3 & 4,8 & 4,6 \\
\hline
\end{tabular}

Fonte: SIM/Secretaria de Saúde de Porto Alegre; *RUSSO; SANTOS, 2010, p. 219.

Gráfico 2: Faixa etária das vítimas de homicídio de Porto Alegre (2006, 2015, 2016 e 2017)

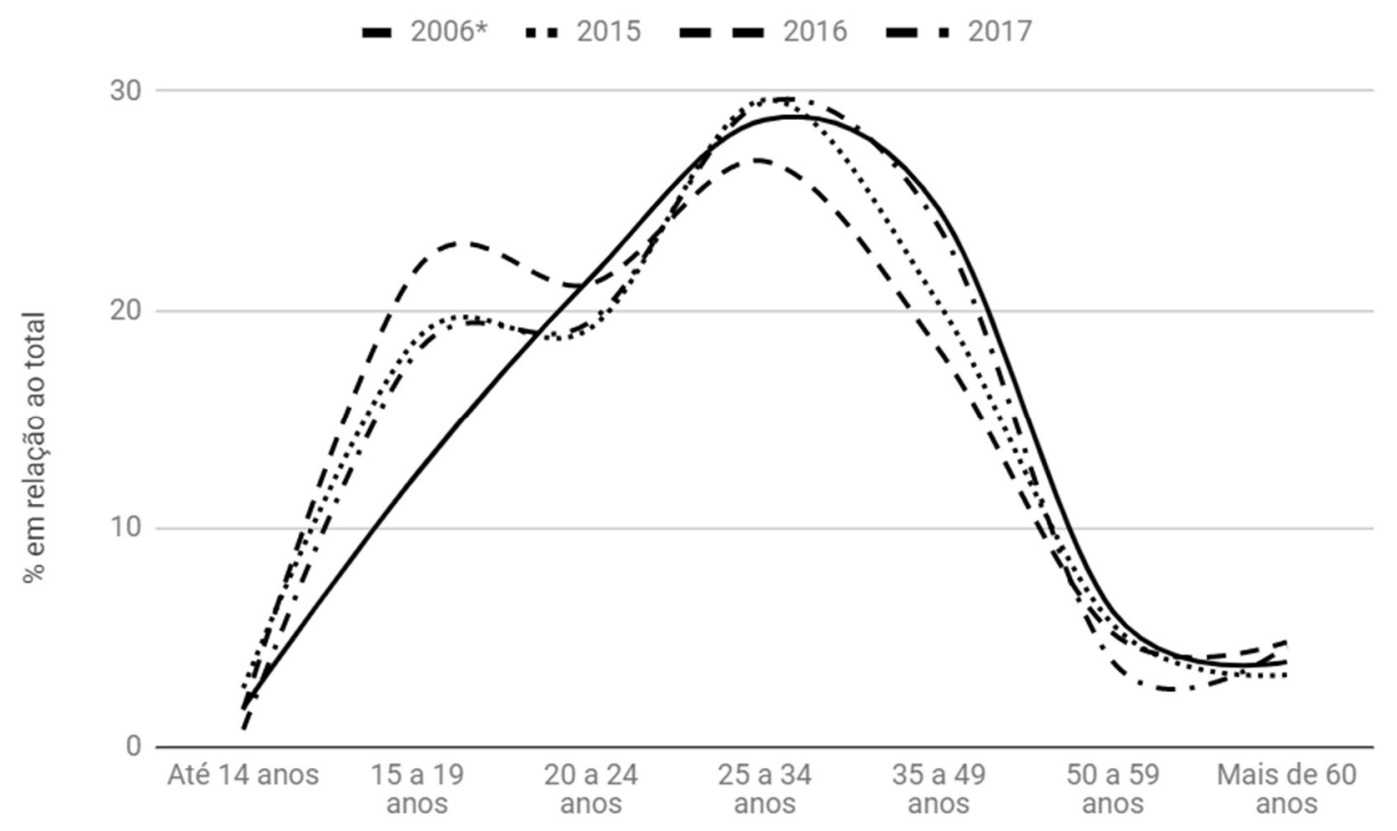

Fonte: SIM/Secretaria de Saúde de Porto Alegre; *RUSSO;SANTOS, 2010, p. 219; elaboração própria.

O gráfico de linhas acima representado indica uma mudança importante na distribuição dos homicídios dos residentes em Porto Alegre também ocorridos na cidade, dez anos após a pesquisa realizada por Santos e Russo. No período compreendido pelos anos recentes analisados), a curva normal do gráfico se deforma e passa a apresentar um pico importante na faixa etária dos 15 aos 19 anos. Assim, apesar dos dados demonstrarem que os homicídios continuam sendo mais representativos na faixa etária entre 25 e 34 anos, os anos recentes apresentam um novo quadro que antecipa para um período bastante anterior a ocorrência dessas mortes.

\subsubsection{Sexo:}

Em relação aos dados do ano de 2015, percebe-se que, quanto à faixa etária de 15 à 29 anos, há uma diferença substancial na frequência de homicídios entre jovens do sexo masculino e 
feminino. Dos 351 jovens residentes em Porto Alegre vítimas de homicídio, apenas 18 corresponderam a morte de jovens do sexo feminino, totalizando $5,1 \%$ do número total de homicídios. Assim, os homicídios de jovens homens moradores na cidade de Porto Alegre, no ano de 2015, totalizaram 333 casos, correspondente a 94,9\% do universo estudado.

Já relativamente aos dados do ano de 2016, percebe-se um aumento no total de número de casos de homicídios na faixa etária estudada, que passaram de 351 à 466 casos, mantendo-se a maior incidência de homicídios entre jovens do sexo masculino. Do número total, apenas 33 corresponderam a morte de jovens do sexo feminino, totalizando 7,1\% dos homicídios, ainda muito inferior em relação à representativa dos jovens do sexo masculino, equivalente à 92,9\% do universo estudado. De todo modo percebeu-se um aumento da representativa das mulheres, o que foi expandido no ano seguinte.

Em 2017, nota-se certa diminuição do número de mortes violentas na cidade. Dos 361 homicídios de jovens ocorridos, 37 correspondem a mortes de jovens do sexo feminino, totalizando 10,3\% das mortes do período, equivalente ao dobro da porcentagem observada no ano de 2015. Já entre os jovens do sexo masculino, chegou-se a um total de 324 casos em 2017, representando $89,7 \%$ das mortes.

A vitimização de jovens do sexo masculino em Porto Alegre alinha-se em parte ao padrão observado no Brasil, no que diz respeito à maioria absoluta do número de mortes por homicídio desta faixa etária ocorrer entre o sexo masculino. O Atlas da Violência do ano de 2018 aponta que dos 33.590 jovens que foram assassinados no Brasil no ano de 2016, 94,6\% eram do sexo masculino, representando um aumento de 7,4\% em relação ao ano de 2015 (FBSP, 2018). A taxa de homicídios entre jovens homens para cada 100 mil jovens também reflete um aumento a partir do ano de 2014: entre 2006 e 2013, a taxa manteve-se em torno de 70, aumentando para 93,5 (2014), 97,8 (2015) e $113,4(2016)$.

\subsubsection{Raça:}

A diferença de letalidade entre negros e o restante da população não apenas é um problema antigo, mas que tem acentuado-se na última década (CERQUEIRA; COELHO, 2017). Enquanto, entre 2006 e 2016, houve um crescimento de $23,1 \%$ na taxa de homicídio de negros, a mortalidade de indivíduos não negros diminuiu 6,8\% (CERQUEIRA, 2018, p. 33). Em 2016, por exemplo, a taxa de homicídios de negros foi duas vezes e meia superior à de não negros (16,0\% contra 40,2\%) (CERQUEIRA, 2018, p. 40).

Jovens negros do sexo masculino continuam sendo assassinados todos os anos como se vivessem em situação de guerra. Aos 21 anos de idade, quando há o pico das chances de uma pessoa sofrer homicídio no Brasil, pretos e pardos possuem $147 \%$ a mais de chances de serem vitimados 
por homicídios (CERQUEIRA; COELHO, 2017, p. 9). De acordo com o Índice de Vulnerabilidade Juvenil à Violência 2017, ano base 2015, em média, jovens negros têm 2,71 mais chances de morrerem por homicídio do que jovens brancos no país, sendo que no Rio Grande do Sul o risco relativo de um jovem negro ser vítima de homicídio em relação a um jovem branco é de 1,3 (FBSP, 2017, p. 27).

Embora a população de Porto Alegre seja predominantemente branca - $79.23 \%$ da população é composta por pessoas brancas, $20,24 \%$ de pessoas negras ${ }^{6}, 0,29 \%$ de pessoas amarelas e $0.23 \%$ por pessoas indígenas ${ }^{7}$ - da análise dos gráficos pode-se perceber que a incidência de homicídios sob a população negra é representativa. No ano de 2015 a porcentagem de jovens negros ${ }^{8}$ moradores na cidade que foram vítimas de homicídio foi de 36,1\%. Já no ano de 2016 a taxa chegou ao valor de 40,3\%, enquanto em 2017 atingiu o patamar de 46,5\%:

Gráfico 3: Percentual de jovens negros e não negros vítimas de homicídio
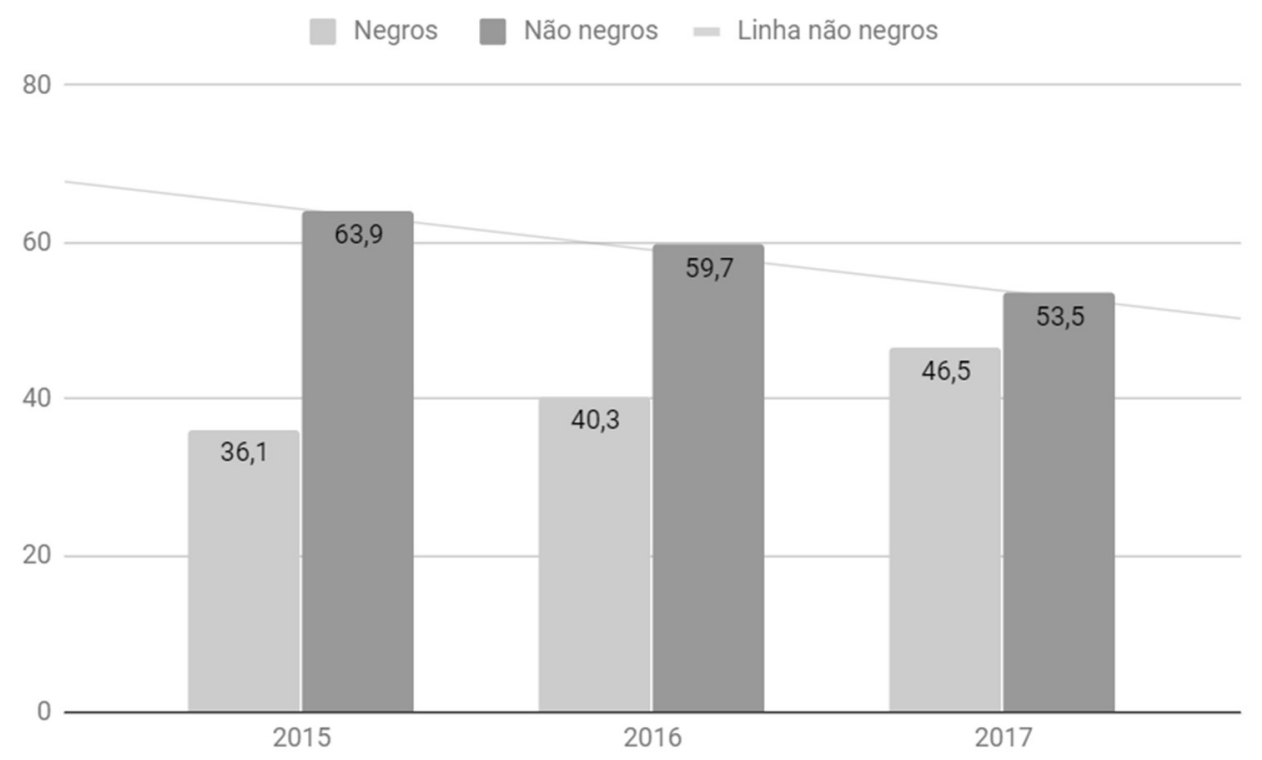

Fonte: SIM/Secretaria de Saúde de Porto Alegre; elaboração própria.

Assim, duas são as tendências verificadas a partir dos dados coletados que se expressam no gráfico a seguir. A curva ascendente da representação dos negros em relação ao conjunto de homicídios dos jovens moradores de Porto Alegre é acompanhada por uma curva descendente da representação dos homens na totalidade das vítimas.

Gráfico 4: Perfil dos homicídios dos jovens residentes em Porto Alegre 


\section{Perfil dos homicídios dos jovens: 2015-2017}

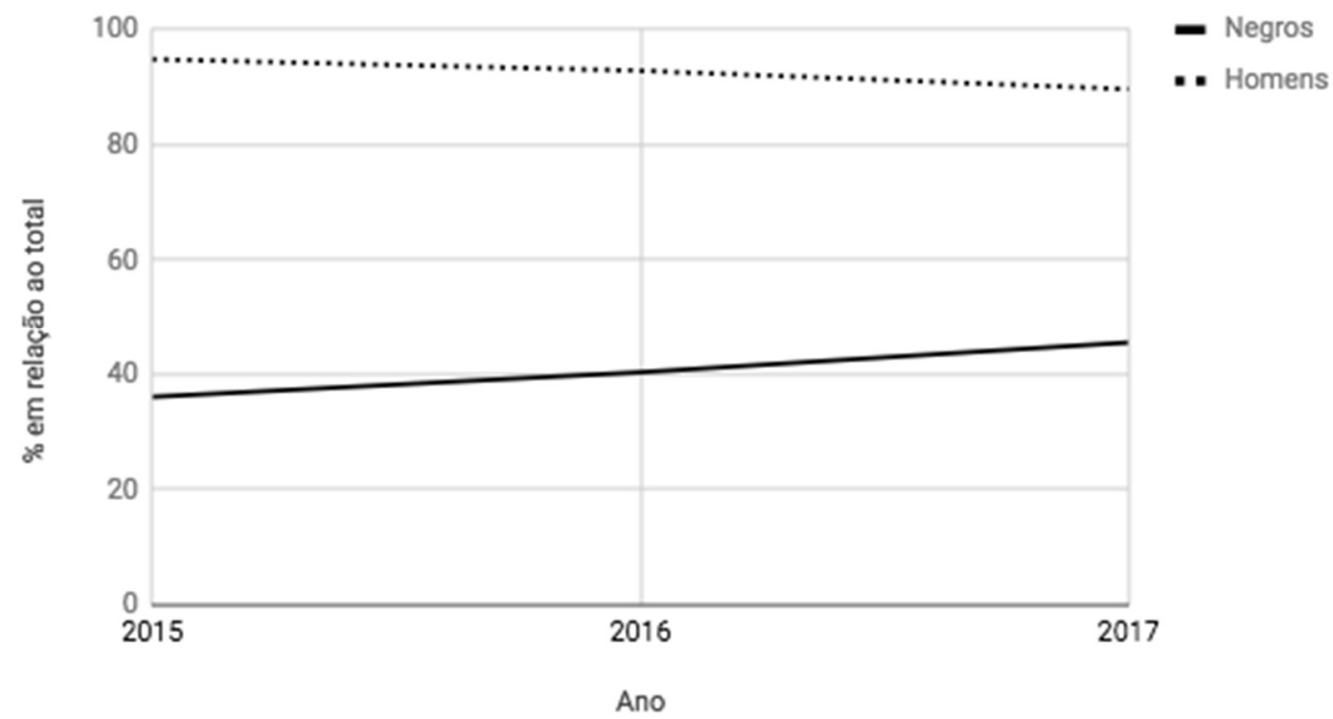

\subsection{Quem mais morre}

A maior incidência de homicídios na população jovem não é propriamente uma novidade no campo da sociologia da violência brasileira. Se, conforme já extensamente demonstrado, são jovens o grupo etário que mais comete violência letal; em tratando-se de homicídios no Brasil parece ser possível, ao generalizar-se, afirmar que se trata substancialmente de homens jovens matando homens jovens (DIRK; MOURA, 2017, p. 4). Esse processo de vitimização letal da juventude no cenário brasileiro institui-se a partir de 1980 e, gradativamente, tem estabelecido-se como um dos principais entraves para o avanço de patamares mínimos de segurança pública no país (CERQUEIRA, 2017, p. 25).

Assim, no Mapa da Violência de 2013 já constava que as taxas de homicídio juvenil não acompanharam os avanços nas políticas de prevenção da violência, tendo aumentado de 42,4 para cada 100 mil jovens em 1998, para 52,4/100 mil em 2013 (WAISELFISZ, 2013, p. 11). De todas as causas de mortalidade, aquelas chamadas de causas externas representaram, em 2011, 73,2\% dos óbitos juvenis (ibidem, p. 20), sendo o homicídio o principal responsável por esse panorama. Assim, apenas na Unidade Federativa do Rio Grande do Sul, os dados demonstram um aumento de 34,5\% de homicídios de pessoas entre 15 e 29 anos entre os anos de 2005 e 2015 (CERQUEIRA, 2017, p. 27), em uma conjuntura que se aproxima dos dados apresentados por essa pesquisa.

As explicações para o fenômeno são muitas e, na medida em que o presente estudo não possui a pretensão de desenvolver as razões, mas apenas apresentar o panorama do perfil das mortes por homicídio na cidade de Porto Alegre, não caberia aqui expor todas as possíveis 
interpretações sociológicas para tal cenário. Destaca-se, todavia, que as características que compõem o perfil dos jovens vítimas de homicídios moradores da capital, em conjunto com a localidade de vida e de morte de tais vítimas possibilitam traçar alguns indicativos de possíveis razões que explicam o aumento dos homicídios da juventude em Porto Alegre nos últimos anos, conforme será feito no item conclusivo deste artigo.

Em relação à maior incidência de morte entre homens, o sexo, é apontado em diversos estudos como característica sócio-demográfica que guarda maior relação com incidência de homicídios (SOARES, 2000). É possível atribuir diversas razões para a ocorrência de um maior número de mortes violentas entre homens em comparação com mulheres, sendo algumas delas a premissa de que homens cometem, de modo geral, mais violência que mulheres (SOARES, 2008); ou que meninos estariam submetidos a menor controle social do que as meninas, o que contribuiria com o maior envolvimento destes em atividades ligadas ao crime (HIRSCHI, 1969); ainda, em razão da "socialização pela violência" ${ }^{9}$ e a necessidade de "neutralização"10 do outro para a afirmação da masculinidade (WALTER-LANG, 2001).

Os dados demonstram que quem mais morre são ainda os jovens do sexo masculino, que correspondem à maioria absoluta de vítimas no número total de homicídios e superam, em grande quantidade, o número de homicídios entre a população jovem feminina. Foi observado, inclusive, um aumento no número total de casos de homicídios no ano de 2016 em relação ao ano e 2015 (mais 115 casos), dos quais 100 ocorreram entre a população jovem do sexo masculino, e 15 entre a do sexo feminino. Em relação ao ano de 2017, houve a diminuição no número total de casos (menos 105 casos), com a diminuição de 109 casos entre a população jovem masculina, e aumento de 4 casos entre a população jovem feminina.

A tendência de que o maior número de homicídios de jovens ocorresse entre a população masculina já era esperada, diante de diversas outras pesquisas que já apontaram o mesmo fenômeno a nível regional e nacional. Uma tendência menos esperada e que merece atenção referese ao aumento percentual entre 2015 e 2017 de jovens mulheres sendo assassinadas. Tal fenômeno é ainda pouco explorado e carece de maior debate. De acordo com o Atlas da Violência (2018), o aumento do número de mulheres assassinadas já pode ser compreendido enquanto uma tendência no Rio Grande do Sul, com o aumento de 90,1\% de casos de assassinatos em apenas 10 anos, no período compreendido entre 2006 e 2016, com os maior número de casos registrados entre 2014 (250 casos), 2015 (284 casos) e 2016 (308 casos). O mesmo estudo atribui como causa o feminicídio ${ }^{11}$, destacando a agressão sexual seguida de morte e homicídios ocorridos em ambientes domésticos. O estudo, contudo, não descarta a existência de outras causas ao fenômeno. Já 
pesquisas mais direcionadas ao contexto de Porto Alegre e centradas sobre as especificidades da faixa etária estudada ainda não foram realizadas.

Em relação à raça daqueles que mais morrem em razão dos homicídios, a concentração das mortes por violência sobre a população negra coloca em xeque o mito de democracia racial muitas vezes defendido. Segundo essa ideia, a discriminação pela cor da pele seria algo irrelevante que não bloquearia oportunidades, não interditaria carreiras e tampouco faria aumentar as chances do indivíduo negro ser assassinado (COELHO; CERQUEIRA , 2017, p. 7). De acordo com o Atlas da Violência 2018 no ano de 2006 a taxa de homicídios de negros por 100 mil habitantes no Rio Grande do Sul era de 19,1, apresentando um crescimento ao longo dos anos chegando em 2016 a 36,8. Já quando se analisa a taxa de homicídios de não negros por 100 mil habitantes no ano de 2006 essa taxa no Rio Grande do Sul era de 17,6 e de 26,2 em 2016 (CERQUEIRA, 2018). Assim, embora a população gaúcha seja predominantemente branca, o acréscimo das mortes por homicídios na última década se concentraram sobre a população negra do estado.

Em tratando-se dos homicídios de negros e de jovens, percebe-se que as diferenças de letalidade contra os afrodescendentes são mais dilatadas no período da juventude. De acordo com o Índice de Vulnerabilidade Juvenil à Violência, em 24 Unidades da Federação brasileira a chance de um jovem negro morrer assassinado é maior do que a de um jovem branco (LIMA; et. al, 2017, p. 28). Torna-se evidente como a desigualdade racial é um fator fundamental para entender-se a forma como a violência no período da juventude manifesta-se no Brasil.

Sinhoretto e Morais, em trabalho sobre violência e racismo no Brasil, afirmam que a análise dos dados disponíveis sobre o fenômeno da morte violenta põe em evidência que a racialização da juventude negra opera a desumanização dos sujeitos, tornando a sua morte plausível e inconsequente (2018, p. 24). Indo além, Cerqueira e Moura, concluem que a busca sobre as explicações das mortes violentas na juventude não podem negligenciar o racismo, ao afirmarem que para além da extinção física, há milhares de mortes simbólicas por trás das perdas de oportunidades e de crescimento pessoal, que muitos indivíduos sofrem apenas pela sua cor de pele (2014, p. 82). São vidas material e simbolicamente perdidas em face do racismo no Brasil.

\subsection{Local de vida e de morte da juventude:}

Com o objetivo de localizar os homicídios de jovens no espaço territorial da cidade de Porto Alegre, optou-se pela construção de mapas como instrumentos ilustrativos dos bairros a) em que residem os jovens vítimas de homicídios; b) em que ocorrem os homicídios ${ }^{12}$. Para que estes mapas fossem produzidos, utilizou-se o Sistema de Informação Geográfica (SIG) de Código Aberto, identificado enquanto "QGIS", da Open Source Geospatial Foundation (OSGEO), uma plataforma livre 
para o desenvolvimento de mapas temáticos através do cruzamento entre documentos na forma de shapelife $e^{13}$ e dados quantitativos.

Os mapas produzidos através programa são capazes de demonstrar geograficamente a incidência das variáveis quantitativas. Assim, no caso do presente trabalho, utilizou-se a shapelife fornecida pela Prefeitura de Porto Alegre, através do seu site oficial ${ }^{14}$, que expressa os limites espaciais do município e sua divisão oficial em 94 bairros, de acordo com a Lei 12.112/2016. Foi realizado um cruzamento entre a shapelife e os dados quantitativos referentes aos locais de residência e de morte por homicídio de jovens da cidade de Porto Alegre, nos anos de 2015, 2016 e 2017, obtidos junto à Secretaria de Saúde.

A opção pelo software permitiu a produção de uma série de mapas demonstrativos de quais bairros havia as maiores e menores concentrações de residências (locais de vida) de jovens assassinados, bem como os bairros nos quais havia a maior e menor incidência de homicídios (locais de morte), no período estudado. Ressalta-se que os índices utilizados referem-se apenas à distribuição dos números absolutos de jovens vítimas de homicídios (tanto em relação ao local em que residem, quanto ao local da morte), de modo que não foram calculadas taxas que levem em conta a proporção de jovens existentes em cada território ${ }^{15}$.

O cruzamento da shapelife com os dados quantitativos necessitou da produção de uma nova tabela ("tabela de correspondência") no programa excell, através da qual fosse possível estabelecer uma coluna em comum entre a tabela de atributos do shapelife e a tabela com os dados quantitativos. Este elemento em comum foi o OBJECTID, que, na tabela de atributos do shapelife, correspondia ao código de cada área delimitada no mapa. Ressalta-se que cada OBJECTID não corresponde necessariamente a um bairro, mas sim a uma área delimitada no mapa, a qual se denomina "área-código". A união entre a shapelife e os dados quantitativos através da correspondência entre o código OBJECTID de cada área do mapa permitiu o cruzamento de dados que demonstrou geograficamente a incidência de residências e locais de morte de jovens assassinados.

No shapelife, existiam 128 divisões em áreas-código, enquanto que os dados quantitativos obtidos junto à Secretaria de Saúde de Porto Alegre estavam expressão em uma divisão de 94 bairros. Houve correspondência entre a maioria das áreas-código previstas na shapelife e os bairros indicados nos dados da Prefeitura, mas, ainda assim, algumas adaptações foram necessárias, sobretudo em relação aos territórios "Arquipélago16", "Jardim Itu-Sabará17" e "Protásio18". Também, os bairros entre os quais não foi possível estabelecer uma correspondência entre as áreas-código do shapelife, e nos quais não havia residências ou mortes por homicídio de jovens foram 
desconsiderados e representados por " 0 " na tabela de correspondência, assim como os dados "ignorados" e "desconhecidos".

O resultado foi a produção de mapas com gradientes de cores que revelam a concentração de residências de vítimas e locais de homicídios em cada bairro de Porto Alegre. Tal gradiente varia entre o preto e o branco, de modo que cada tom representa uma concentração, classificada em baixa (branco), intermediária (cinza claro), alta (cinza escuro) e muito alta (preto). O próprio software QGIS define as quebras naturais, a partir da utilização do sistema jenks. As quebras naturais são definidas a partir dos números de concentrações encontrados (por exemplo: concentrações que se repetem, número máximo e número mínimo de concentrações).

Imagem 1: Territórios onde residem os jovens vítimas de homicídio
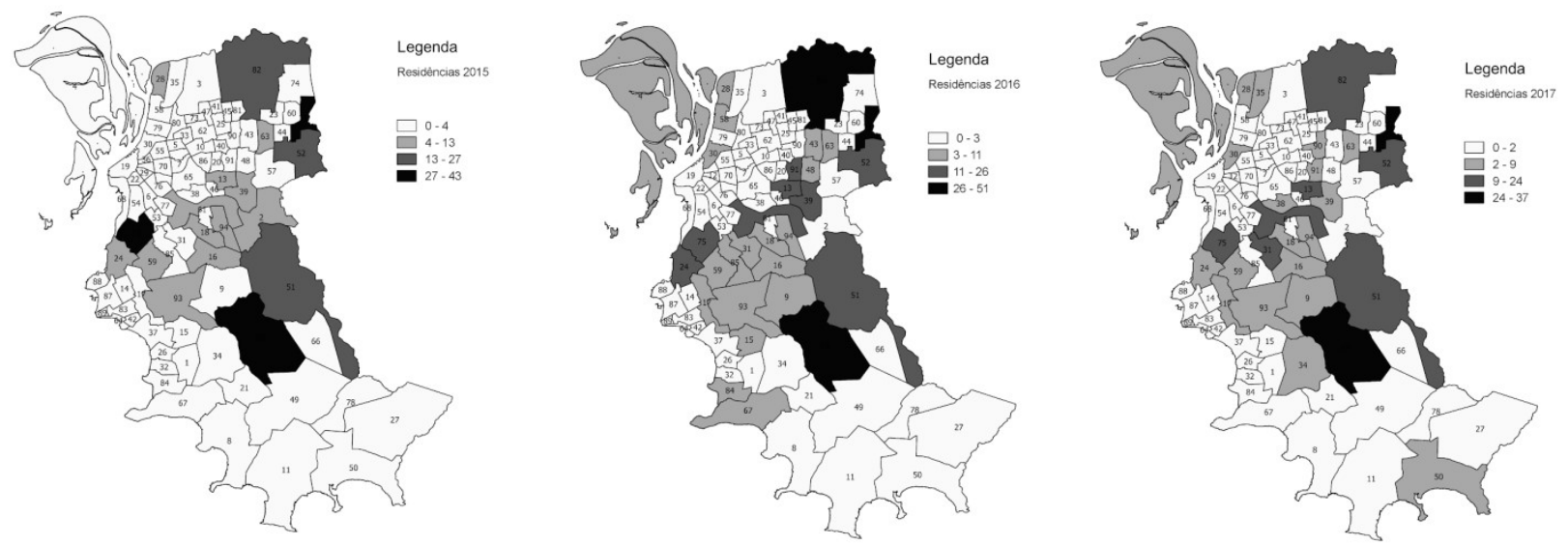

Tabela 3: Legenda dos territórios de Porto Alegre

\begin{tabular}{|c|c|c|c|c|c|c|c|c|c|}
\hline $\begin{array}{c}\text { Aberta } \\
\text { Morros }\end{array}$ & 1 & $\begin{array}{c}\text { Chapéu do } \\
\text { Sol }\end{array}$ & 21 & Jardim Floresta & 41 & Partenon & 61 & $\begin{array}{c}\text { São } \\
\text { Sebastião }\end{array}$ & 81 \\
\hline Agronomia & 2 & $\begin{array}{c}\text { Cidade } \\
\text { Baixa }\end{array}$ & 22 & Jardim Isabel & 42 & $\begin{array}{c}\text { Passo das } \\
\text { Areia }\end{array}$ & 62 & Sarandi & 82 \\
\hline Anchieta & 3 & $\begin{array}{c}\text { Costa e } \\
\text { Silva }\end{array}$ & 23 & Jardim Sabará & 43 & $\begin{array}{c}\text { Passo das } \\
\text { Pedras }\end{array}$ & 63 & Sétimo Céu & 83 \\
\hline Arquipélago & 4 & Cristal & 24 & Jardim & 44 & Pedra & 64 & Serraria & 84 \\
\hline
\end{tabular}




\begin{tabular}{|c|c|c|c|c|c|c|c|c|c|}
\hline Auxiliadora & 5 & $\begin{array}{c}\text { Cristo } \\
\text { Redentor }\end{array}$ & 25 & Jardim Lindóia & 45 & Petrópolis & 65 & Teresópolis & 85 \\
\hline Azenha & 6 & $\begin{array}{l}\text { Espírito } \\
\text { Santo }\end{array}$ & 26 & Jardim do Salso & 46 & Pitinga & 66 & $\begin{array}{c}\text { Três } \\
\text { Figueiras }\end{array}$ & 86 \\
\hline Bela Vista & 7 & Extrema & 27 & $\begin{array}{l}\text { Jardim São } \\
\text { Pedro }\end{array}$ & 47 & Ponta Grossa & 67 & Tristeza & 87 \\
\hline Belém Novo & 8 & Farrapos & 28 & Jardim Itu & 48 & Praia de Belas & 68 & $\begin{array}{c}\text { Vila } \\
\text { Assunção }\end{array}$ & 88 \\
\hline Belém Velho & 9 & Farroupilha & 29 & Lageado & 49 & Restinga & 69 & $\begin{array}{c}\text { Vila } \\
\text { Conceição }\end{array}$ & 89 \\
\hline Boa Vista & 10 & Floresta & 30 & Lami & 50 & Rio Branco & 70 & Vila Ipiranga & 90 \\
\hline Boa Vista Sul & 11 & Glória & 31 & $\begin{array}{l}\text { Lomba do } \\
\text { Pinheiro }\end{array}$ & 51 & Rubem Berta & 71 & Vila Jardim & 91 \\
\hline Bom Fim & 12 & Guarujá & 32 & $\begin{array}{c}\text { Mario } \\
\text { Quintana }\end{array}$ & 52 & Santa Cecília & 72 & $\begin{array}{c}\text { Vila João } \\
\text { Pessoa }\end{array}$ & 92 \\
\hline Bom Jesus & 13 & $\begin{array}{l}\text { Higienópoli } \\
\text { s }\end{array}$ & 33 & Medianeira & 53 & $\begin{array}{c}\text { Santa Maria } \\
\text { Goretti }\end{array}$ & 73 & Vila Nova & 93 \\
\hline Camaquã & 14 & Hípica & 34 & Menino Deus & 54 & $\begin{array}{c}\text { Santa Rosa de } \\
\text { Lima }\end{array}$ & 74 & São José & 94 \\
\hline Campo novo & 15 & Humaitá & 35 & $\begin{array}{l}\text { Moinhos de } \\
\text { Vento }\end{array}$ & 55 & Santa Tereza & 75 & & \\
\hline Cascata & 16 & $\begin{array}{l}\text { Independê } \\
\text { ncia }\end{array}$ & 36 & Mon't Serrat & 56 & Santana & 76 & & \\
\hline Cavalhada & 17 & Ipanema & 37 & Morro Santana & 57 & Santo Antônio & 77 & & \\
\hline
\end{tabular}




\begin{tabular}{|c|c|c|c|c|c|c|c|c|}
$\begin{array}{c}\text { Cel. Aparício } \\
\text { Borges }\end{array}$ & 18 & $\begin{array}{c}\text { Jardim } \\
\text { Botânico }\end{array}$ & 38 & Navegantes & 58 & São Caetano & 78 & \\
\hline Centro & 19 & $\begin{array}{c}\text { Jardim } \\
\text { Carvalho }\end{array}$ & 39 & Nonoai & 59 & São Geraldo & 79 & \\
\hline $\begin{array}{c}\text { Chácara das } \\
\text { Pedras }\end{array}$ & 20 & $\begin{array}{c}\text { Jardim } \\
\text { Europa }\end{array}$ & 40 & $\begin{array}{c}\text { Parque Santa } \\
\text { Fé }\end{array}$ & 60 & São João & 80 & \\
\hline
\end{tabular}

Conforme observa-se, os mapas das residências e locais de morte dos jovens vítimas de homicídio sofre alterações ao longo da série temporal analisada. A presente análise irá apontar três questões principais: distribuição das residências das vítimas em toda a cidade, locais que apresentam os maiores índices de homicídios de jovens; continuidade ou descontinuidade de tais índices ao longo dos anos. Em relação ao primeiro ponto, 6 bairros despontam como os locais em que mais residem jovens assassinados considerando os três anos pesquisados em conjunto: Restinga, Santa Tereza, Rubem Berta, Sarandi, Lomba do Pinheiro e Mario Quintana.

Tabela 4: Distribuição da residência dos jovens vítimas de homicídio nos bairros com maior incidência

\begin{tabular}{|l|l|l|l|l|l|l|l|}
\hline & Restinga & $\begin{array}{l}\text { Santa } \\
\text { Tereza }\end{array}$ & $\begin{array}{l}\text { Rubem } \\
\text { Berta }\end{array}$ & Sarandi & Lomba & $\begin{array}{l}\text { Mario } \\
\text { Quintana }\end{array}$ & $\begin{array}{l}\text { Total } \\
\text { Total }\end{array}$ \\
\hline 2015 & $37(10,5 \%)$ & $33(9,4 \%)$ & $43(12,3 \%)$ & $16(4,6 \%)$ & $23(6,6 \%)$ & $27(7,6 \%)$ & 51 \\
\hline 2016 & $51(10,9 \%)$ & $23(4,6 \%)$ & $43(9,2 \%)$ & $35(7,5 \%)$ & $23(4,9 \%)$ & $26(5,6 \%)$ & 42,7 \\
\hline 2017 & $37(10,2 \%)$ & $18(5 \%)$ & $32(8,8 \%)$ & $19(5,3 \%)$ & $24(6,6 \% \%)$ & $22(6,1 \%)$ & 41,2 \\
\hline
\end{tabular}

A tabela acima apresenta os números absolutos de jovens residentes nos bairros que foram vítimas de homicídio e, entre parênteses, a representação desse número no total de homicídios. Ao final, indica-se a representação dos 6 bairros em conjunto do total da cidade de Porto Alegre (dividida na presente pesquisa em 94 territórios). Diante de tais dados, observa-se que o bairro Rubem Berta aparece como principal local de residência no ano de 2015 e a Restinga com os maiores índices em 2016 e 2017 (tanto em relação ao número absoluto, quanto proporcionalmente). 
Em 2016, todos os 6 territórios apresentaram aumento nos números ou, ao menos, mantiveram-se no mesmo patamar, com exceção do bairro Mario Quintana que apresentou um jovem residente a menos vítima de homicídio. No ano seguinte, contudo, todos os índices caíram tanto em relação ao ano anterior, como em relação ao ano de 2015. Também houve um considerável decréscimo na concentração da residência dos jovens ao longo dos anos: se em 2015 os 6 territórios conjuntamente representavam 51\% dos locais de moradia de todos os jovens assassinados, demonstrando um fenômeno social espacialmente concentrado; em 2017 esse número caiu para $41,2 \%$. Ao que tudo indica, portanto, tem havido um certo espraiamento pela cidade dos locais de residência das vítimas, o que é visualmente perceptível nos mapas apresentados. Sobre esse aspecto, destaca-se, por exemplo, que o bairro Glória apresenta o oitavo pior índice no ano de 2017, com 11 jovens residentes vítimas de homicídio, representando 3\% do total dos bairros, quando em 2015 esse número foi de apenas 0,3\% e em 2016, 1,1\%.

Conforme demonstrou-se, mesmo que haja uma concentração bastante significativa em certos territórios - o que certamente possui relação com questões socioeconômicas próprias, as quais serão superficialmente aventadas na conclusão do presente artigo - os locais de residência dos jovens vitimados vêm alastrando-se por outros territórios, o que parece ser indicativo de algum novo fator explicativo da violência letal da juventude, ainda carente de compreensão. Assim, o bom indicativo da diminuição do número total de jovens vítimas de homicídio no ano de 2017 vem acompanhado de um mapa da cidade em que as residências de tais sujeitos, apesar de em grande parte ainda localizarem-se em bairros conhecidos pelos altos índices de violência letal, estão também distribuídas em espaços que até então não vinham perdendo tantos jovens para a mortalidade violenta. Para melhor compreender esse "novo" cenário, faz-se necessário observar os mapas da cidade referente aos "locais de morte" desses jovens, isto é, locais identificados pelo SIM como área de ocorrência do evento violento. 
Imagem 2: Territórios onde ocorreram os homicídios dos jovens moradores de Porto Alegre
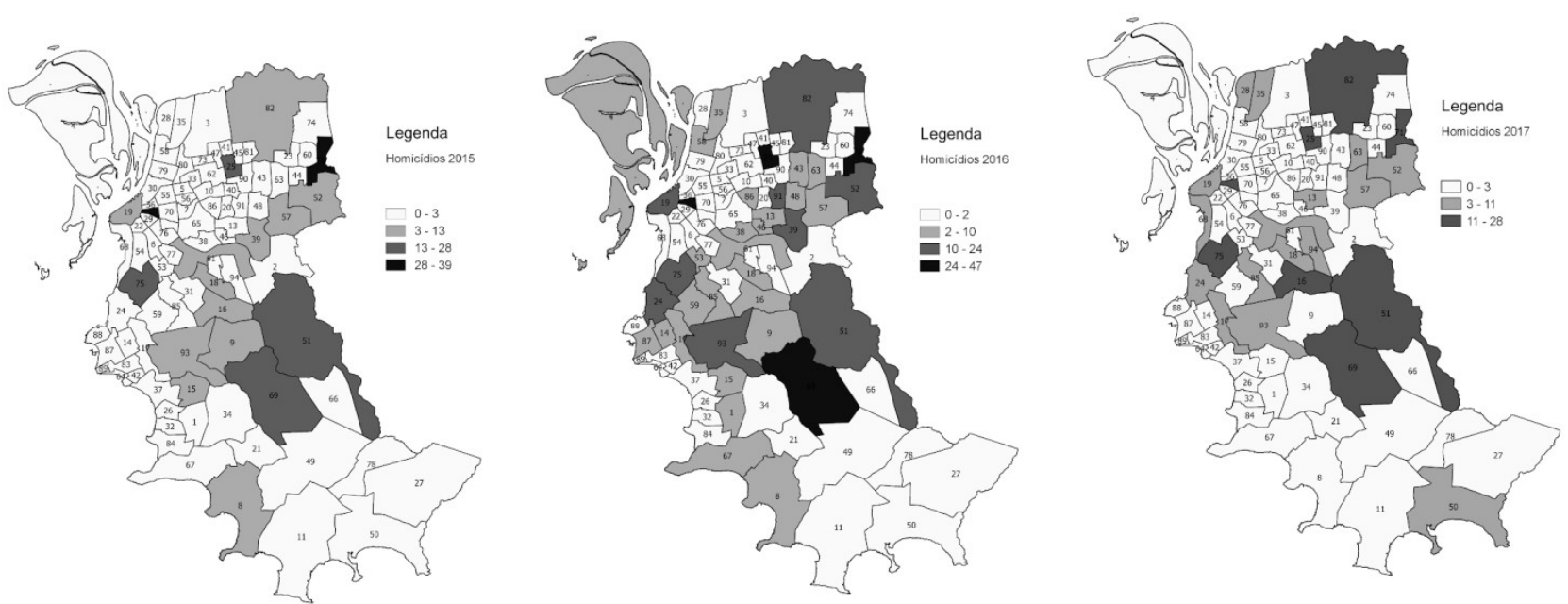

Quanto à incidência de homicídios de jovens residentes em Porto Alegre, percebe-se que a maioria absoluta destes ocorreu dentro município: no ano de 2015, 92,2\% dos casos ocorreram na cidade, havendo um aumento para 92,9\% em 2016, e diminuição para 90,9\% em 2017. Os demais homicídios foram registrados em locais fora da cidade, na região metropolitana, serra, litoral gaúcho, e outros estados do país. Em relação às ocorrências fora do Rio Grande do Sul, não houve registros no ano de 2015. Já em 2016, 1 caso foi registrado em Osasco (SP), e em 2017, 1 caso em Vilhena (RO) e 5 casos em cidades de Santa Catarina, proporcional a 0,9\% dos homicídios do período. Os demais homicídios foram registrados em cidades do Rio Grande do Sul, conforme observa-se no mapa abaixo:

Imagem 3: Distribuição de homicídios de jovens residentes em Porto Alegre no estado do Rio Grande do Sul
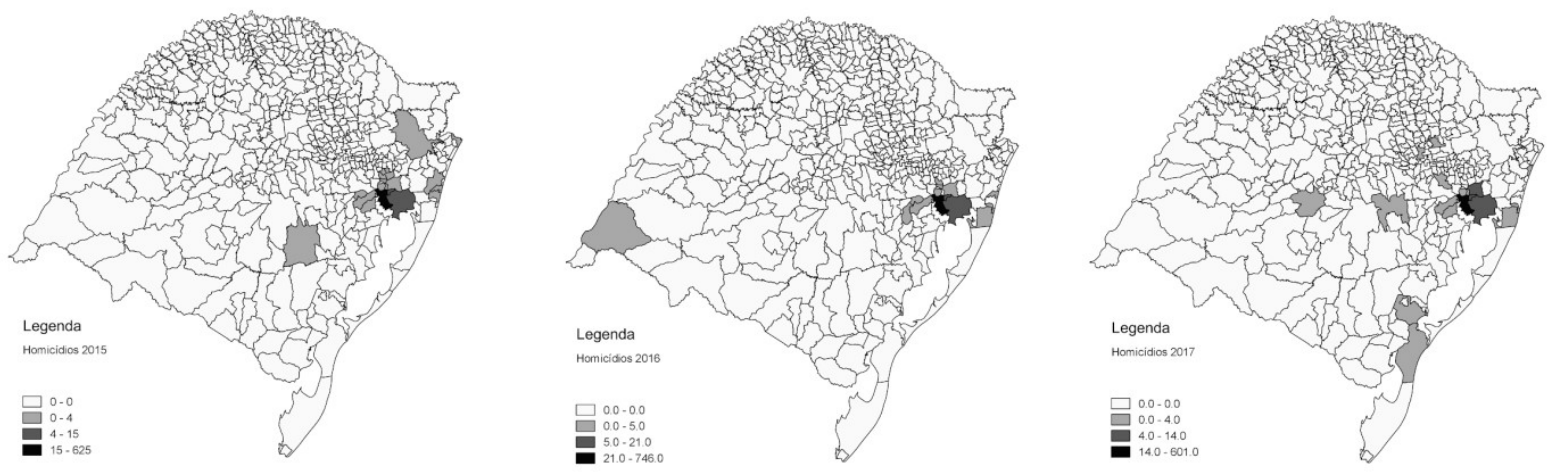
A maioria destes ocorreram na região metropolitana de Porto Alegre, destacando-se as cidades de Alvorada, Gravataí e Viamão. Em 2015, 9 homicídios foram registrados em Alvorada (1,3\%), 3 em Gravataí (0,4\%) e 15 em Viamão (2,2\%). Em 2016, houve aumento de casos em Alvorada, com 21 mortes registradas (2,6\%), enquanto Gravataí e Viamão registraram uma leve queda na distribuição proporcional $(0,2 \% ; 1,6 \%)$ de casos. Em 2017, verificou-se uma diminuição na frequência de homicídios em Alvorada, que contou com 10 homicídios (1,5\%), e aumento em Gravataí, com 10 mortes registradas (1,5\%), enquanto Viamão manteve a média dos outros anos, com 14 homicídios (2,1\%).

Em relação às ocorrências registradas na cidade de Porto Alegre, 7 bairros despontam como os locais de maior concentração de homicídios registrados entre jovens nascidos na cidade: Rubem Berta, Bom Fim, Cristo Redentor, Restinga, Santa Tereza, Lomba do Pinheiro e Sarandi.

Tabela 5: Distribuição dos homicídios entre jovens nos bairros com maior incidência

\begin{tabular}{|c|c|c|c|c|c|c|c|c|}
\hline & $\begin{array}{c}\text { Rubem } \\
\text { Berta }\end{array}$ & Bom Fim & $\begin{array}{c}\text { Cristo } \\
\text { Redentor }\end{array}$ & Restinga & $\begin{array}{c}\text { Santa } \\
\text { Tereza }\end{array}$ & $\begin{array}{c}\text { Lomba do } \\
\text { Pinheiro }\end{array}$ & $\begin{array}{c}\text { Sarandi } \\
\text { total }\end{array}$ \\
\hline 2015 & $35(10 \%)$ & $39(11,1 \%)$ & $28(8 \%)$ & $25(7,1 \%)$ & $27(7,7 \%)$ & $19(5,4 \%)$ & 13 & 53 \\
$(3,7 \%)$ & & & & & & & \\
\hline 2016 & $47(10,1 \%)$ & $33(7,1 \%)$ & $33(7,1 \%)$ & $30(6,4 \%)$ & $22(4,7 \%)$ & $21(4,5 \%)$ & 24 & 45 \\
\hline 2017 & $28(7,8 \%)$ & $20(5,5 \%)$ & $23(6,4 \%)$ & $28(7,8 \%)$ & $18(5 \%)$ & $16(4,4 \%)$ & 15 & 41 \\
& & & & & & & & \\
\hline
\end{tabular}

A tabela acima apresenta em números absolutos a quantidade de homicídios ocorridos em cada bairro e, entre parênteses, a representação desse número no total de homicídios da cidade. Ao final, indica-se a representação dos 7 bairros em conjunto em relação ao total da cidade de Porto Alegre. Diante de tais dados, observa-se que o bairro Bom Fim aparece como principal local de homicídios no ano de 2015, enquanto o bairro Rubem Berta apresenta os maiores índices em 2016 e 2017, tanto em números absolutos quanto proporcionalmente.

Ocorre que, os 39 casos de homicídios registrados no Bom Fim no ano de 2015 tiveram como registro de local de ocorrência o hospital ${ }^{19}$. O mesmo ocorreu em relação ao bairro Cristo Redentor, em que os 28 casos registrados ocorreram no hospital. O padrão se repetiu nos dois anos seguintes 
(todas as mortes de ambos os bairros ocorreram no hospital). Assim, uma primeira questão relevante diz respeito aos padrões de registros utilizados nas Declarações de Óbitos. Um número relevante de casos indicados como homicídios foram registrados como tendo ocorrido nos bairros dos hospitais em que as vítimas foram atendidas, ${ }^{20}$ o que produz uma distorção nos dados do SIM. São eventos que acabam tendo sua localização desconhecida, dificultando a análise territorial da ocorrência de homicídios da cidade.

Em comparação aos locais de residência dos jovens, verifica-se que 5 destes também aparecem também enquanto os locais de maior incidência de homicídios: Restinga, Santa Tereza, Rubem Berta, Sarandi, Lomba do Pinheiro. Dentre estes, destaca-se o bairro Rubem Berta que, ao longo de todos os anos estudados, apresentou a segunda maior concentração de residentes assassinados (104) e a maior ocorrência de homicídios entre jovens (110), em números absolutos.

Quanto à evolução ao longo dos anos estudados, 2016 foi o ano de maior incidência de homicídios, verificando-se o aumento de ocorrências em relação ao ano de 2015 proporcional e absoluto em todos os 7 bairros, com exceção dos bairros Bom Fim e Santa Tereza, que apresentaram, respectivamente, 4 e 5 jovens assassinados a menos. Em 2017, todos os índices caíram em relação à 2016, em especial, no bairro Rubem Berta, no qual houve um decréscimo de 19 homicídios registrados. O decréscimo verificado em 2017 também ocorreu em relação ao ano de 2015, à exceção dos bairros Restinga e Sarandi.

Tal como verificado em relação às residências, também houve um considerável decréscimo na concentração de homicídios no grupo de bairros apontados: se em 2015 os territórios conjuntamente representavam 53\% dos locais onde ocorreram os homicídios dos jovens de Porto Alegre, em 2017 esse número caiu para 41,2\%. Essa distribuição menos concentrada seguiu padrões muito semelhantes àqueles observados no caso dos locais em que habitavam os jovens vítimas de homicídio.

\section{CONCLUSÃO}

Em um primeiro momento, a pesquisa buscou demonstrar qual o perfil das vítimas de homicídio residentes na cidade de Porto Alegre, identificando quais os critérios que tornam um indivíduo mais vulnerável a sofrer esse tipo de violência letal. Da análise dos dados obtidos, três critérios foram identificados como mais relevantes: (i) idade; (ii) sexo; e (iii) raça. Uma primeira conclusão possível, portanto, confirma outros estudos já realizados em que se constatou que o perfil das vítimas de homicídios é constituído de três características básicas: homem, jovem, negro.

Em relação à cidade de Porto Alegre, verificou-se que mais de metade das vítimas de homicídio são jovens, entre com idade entre 15 e 29 anos. O ano de 2016 contou com a maior representação da juventude na totalidade dos homicídios, correspondendo a 58\%. As idades de 
maior risco variam conforme o ano analisado: no ano de 2015 a faixa etária crítica manteve-se entre 17 e 21 anos; em 2016, entre 16 e 21 anos. Já em 2017, identificou-se picos nas idades de 21, 23 e 28 anos. Ademais, no triênio analisado na presente pesquisa observou-se uma maior concentração de vítimas com idades entre 15 e 19 anos, o que não foi a realidade observada em pesquisa realizada na cidade no ano de 2006 (RUSSO; SANTOS, 2010). Assim, parece importante o fato de que as vítimas são cada vez mais jovens, evidenciando um panorama em que sujeitos na primeira fase da adolescência estão muito expostos à violência homicida.

Quanto à distribuição em relação ao sexo, percebe-se que a maioria absoluta de homicídios entre jovens envolveu indivíduos do sexo masculino. A concentração proporcional de homicídios em relação a homens é evidente, e manteve-se em torno dos $90 \%$ ao longo de todos os anos estudados. Verificou-se, todavia, diminuição na concentração de eventos entre jovens do sexo masculino ao longo dos anos e o consequente aumento do número de casos entre jovens do sexo feminino. Assim, o ano de 2015 apresentou a maior concentração de homicídios entre jovens do sexo masculino $(94,9 \%)$ e 2017 a menor concentração (89,7\%), totalizando uma diminuição percentual de 5,2\% ao longo do período estudado. Esse panorama parece indicar uma maior importância dos casos de feminicídios na totalidade de mortes violentas da cidade, bem como em reconfigurações dos eventos homicidas que têm por vitimizar mais meninas ou mulheres.

Quanto ao perfil racial de jovens assassinados, percebe-se que, apesar da população na cidade de Porto Alegre ser predominantemente branca - 79,23\% de pessoas brancas, contra apenas 20,24\% de pessoas negras - a porcentagem de jovens negros assassinados foi 36,1\% em 2015, aumentando para 40,3\% em 2016, e atingindo o patamar de 46,5\% em 2017. Ou seja, foi verificado um aumento percentual de 10,4\% ao longo dos anos estudados. A tendência de aumento quanto aos índices de mortalidade entre jovens negros e a diminuição entre jovens brancos demonstra a diferença substancial quanto às trajetórias de vida enfrentadas por cada um destes grupos: é como se estes vivessem "em cidades ou países distintos", ou, em outras palavras, em um território que os vulnerabiliza em função do critério racial. Tal critério é o único em que se evidencia uma curva ascendente importante e, por isso, parece ser um dos mais relevantes de serem observados no combate da mortalidade e violência entre jovens.

Quanto aos locais de vida e morte dos jovens de Porto Alegre, verifica-se que a maioria absoluta e proporcional de homicídios - em torno de $90 \%$ ao longo dos anos estudados - concentrase na cidade de Porto Alegre, seguida pela região metropolitana (Alvorada, Gravataí e Viamão), e, por fim, em outros estados, como cidades da região litorânea de Santa Catarina. Em relação à cidade de Porto Alegre, 6 bairros despontam como os locais em que mais residem jovens assassinados, 5 destes também aparecendo enquanto locais onde mais morrem jovens residentes de Porto Alegre. 
Estes 5 territórios em comum - Rubem Berta, Restinga, Santa Tereza, Sarandi e Lomba do Pinheiro são, portanto, os locais de maior risco para jovens na cidade de Porto Alegre.

Assim, apesar de notar-se uma dispersão cada vez maior dos locais de vida e de morte dos jovens pelos bairros da cidade, a concentração dos eventos nestes 5 territórios não foi menor que $30 \%$ nos três anos estudados, o que evidencia um foco bastante específico de bairros vitimizados pelas mortes violentas na cidade. Parece evidente a necessidade de concentrar-se esforços das políticas públicas para uma melhor assistência nesses locais, já marcados por níveis de desenvolvimento social bastante precários.

Ainda chama atenção o fato de que o bairro Mario Quintana apresentou taxas importantes de jovens vítimas de homicídio que habitavam no local, com uma média de 6,5\% em relação ao total de bairros da cidade. Entretanto, a representação de homicídios ocorridos no bairro manteve-se próximo dos 3\%, indicando que jovens que moravam no Mario Quintana acabaram por ser vítimas de homicídios em outros locais. Uma possível explicação para essa distorção pode estar na identificação de muitos eventos de morte nos bairros Bom Fim e Cristo Redentor, embora estes sejam os locais dos hospitais em que as vítimas foram atendidas antes de virem a óbito e não locais de ocorrência da violência homicida.

Por fim, cabe reforçar o argumento já apresentado anteriormente de que a presente pesquisa não busca apontar fatores causais dos homicídios na cidade de Porto Alegre, mas sim indicar características importantes dos perfis das vítimas, bem como apresentar uma representação espacial do local de vida e morte destes eventos. Em que pese se possa aventar possíveis fatores relevantes na explicação do aumento dos homicídios e da sua maior dispersão pela cidade - como a reconfiguração do tráfico de drogas ocorrida na cidade a partir de 2016 (CIPRIANI, 2017) - seriam precisos pesquisas qualitativas mais aprofundadas que pudessem dar conta da complexidade desses eventos, identificando suas motivações, por exemplo. Assim, espera-se que a presente pesquisa contribua como uma primeira análise do cenário, mas que novas investigações sociais sobre a temática sejam realizadas de forma atenta à realidade da capital gaúcha.

\section{NOTAS}

[1] ZERO HORA, Porto Alegre é listada entre as cidades mais violentas do mundo. Publicado em: 02.04.2017. Acesso em: 17. 09.2018. Disponível em:

<https://gauchazh.clicrbs.com.br/seguranca/noticia/2017/04/porto-alegre-e-listada-entre-ascidades-mais-violentas-do-mundo-9762767.html>

[2] O SPSS é um software que realiza o compilamento de dados, executando desde estatísticas descritivas a métodos avançados, podendo também gerar tabelas e gráficos. 
[3] O CVLI considera a soma das vítimas de homicídio doloso, lesão corporal seguida de morte e latrocínio.

[4] Conforme descrito na publicação "a categoria Mortes Violentas Intencionais (MVI) corresponde à soma das vítimas de homicídio doloso, latrocínio, lesão corporal seguida de morte e mortes decorrentes de intervenções policiais em serviço e fora (em alguns casos, contabilizadas dentro dos homicídios dolosos, conforme notas explicativas)" (FBSP, 2017, T.13).

[5] Apenas neste caso, portanto, foram excluídos os casos de jovens mortos em outras cidades.

[6] A categoria negra é a junção de duas outras categorias utilizadas pelo IBGE: preta e parda.

[7] Fontes: Coordenação de Cartografia - SMAMS - Secretaria Meio Ambiente e Sustentabilidade/ Prefeitura de Porto Alegre; IBGE.

[8] Na análise que segue, adotamos a classificação do IBGE para raça/cor, em que consideramos negros os indivíduos de cor preta ou parda; e indivíduos não negros, os brancos, indígenas ou amarelos.

[9] A violência, de acordo com o autor, se perpetua nas relações masculinas enquanto substrato e produto dos processos de socialização típicos experimentados pelos homens.

[10] A afirmação da masculinidade enquanto parte do processo de socialização e construção da identidade masculina perpassa pela neutralização de outros homens, o que explicaria, em parte, porque homens estariam sujeitos a maior risco de serem assassinados por outros homens.

[11] Tipo penal previsto no art. 121, §20, inciso VI do Código Penal.

[12] Locais identificados pelo Sistema de Informação sobre Mortalidade como sendo locais de ocorrência da morte violenta.

[13] Formato de arquivo de dados geoespaciais em forma de vetor que pode ser utilizado pelo Sistema de Informações Geográficas - SIG

[14] Material obtido junto ao site da Prefeitura de Porto Alegre. Acesso: <http://www2. portoalegre.rs.gov.br/spm/default.php?p_secao=297> em novembro de 2018

[15] A construção de taxas de homicídio juvenil não foi realizada pela ausência de dados referentes ao número de jovens que residem em cada bairro em cada um dos anos pesquisados. Ademais, entende-se que o homicídio é um evento que, dada sua extraordinariedade, pode ser trabalhado apenas a partir dos números absolutos.

[16] Em virtude de suas divisões naturais em áreas menores e pequenas ilhas, o território "Arquipélago" contou com 33 áreas-código. Para realizar a interação, produziu-se uma tabela com todos os códigos OBJECTID correspondentes às áreas-código, que, em conjunto, formavam o bairro. Reproduziu-se para cada um dos códigos na tabela de correspondência o mesmo número, correspondente ao número de residências de cada ano estudado, de modo que, no mapa, a 
representação ficou a mesma para toda a área do bairro. Assim, o número de mortes representado corresponde ao número total de todo o bairro Arquipelágo, e não de cada ilha individualmente.

[17] No shapelife existia a divisão entre "Jardim Itú" e "Jardim Sabará", enquanto que, nos dados da prefeitura, ambas as regiões correspondiam a um bairro. Também em relação a estes foi reproduzido para ambos os códigos OBJECTID o mesmo número de residências em cada ano, gerando a equivalência na representação contida no mapa para toda a área do bairro.

[18] Os dados do SIM faziam referência à região-bairro "Protásio Alves", sem qualquer correspondência às áreas-código da shapelife. A localidade se refere à Unidade de Saúde Jardim Protásio Alves (US Jardim Protásio Alves)\#, localizada no bairro Mario Quintana. Assim, considerando que número de residências na região "Protásio Alves" era significativamente menor que no bairro Mario Quintana, bem como que a US Jardim Protásio Alves se localizava no bairro Mario Quintana, somou-se o número de residências destas duas localidades, que restou representado conjuntamente no bairro "Mario Quintana".

[19] Para tal análise, foram cruzados no SPSS as variáveis "Local de ocorrência do óbito" (lococor) com "Bairro de Ocorrência" (baiocor). A variável "Local de ocorrência do óbito" possui os seguintes códigos: 1-hospital; 2-outros estabelecimentos de saúde; 3-domicílio; 4-via pública; 5-outros; 9ignorado.

[20] Nota-se que no bairro Bom-fim localiza-se o Hospital de Pronto Socorro de Porto Alegre, sendo o hospital de referência para atendimentos de emergência e trauma. Já no Bairro Cristo Redentor encontram-se dois outros importantes hospitais públicos federais: Hospital Cristo Redentor e Hospital Conceição, também referências para emergências na Zona Norte da cidade.

\section{REFERÊNCIA BIBLIOGRÁFICAS}

CERQUEIRA, Daniel. et al. Atlas da Violência 2018. Rio de Janeiro: Fórum Brasileiro de segurança pública., 2018.

Atlas da Violência 2017. Rio de Janeiro: Fórum Brasileiro de segurança pública, 2017.

CERQUEIRA, Daniel; COELHO Danilo Santa Cruz. Democracia racial e homicídios de jovens negros na cidade partida. Brasília: IPEA, 2017.

DE CASTRO CERQUEIRA, Daniel Ricardo; DE MOURA, Rodrigo Leandro. Vidas perdidas e racismo no Brasil. Publicatio UEPG: Ciências Sociais Aplicadas, v. 22, n. 1, p. 73-90, 2014.

CIPRIANI, Marcelli. Segregação Sócio-espacial e territorialidades do tráfico de drogas: as "facções criminais" diante do espaço urbano. Revista Conversas e Controvérsias, Porto Alegre, v. 3, n. 2, p. 528, 2017. 
DIRK, Renato; MOURA, Lílian de. As motivações nos casos de letalidade violenta da Região Metropolitana do Rio de Janeiro. Cadernos de Segurança Pública, v. 9, n. 08, 2017.

FEE, Fundação de Economia e Estatística. Estimativas Populacionais (Revisão 2018). Acesso em: 14.01.2019. Disponível em: <https://www.fee.rs.gov.br/indicadores/populacao/estimativaspopulacionais-revisao-2018/>

HIRSCHI, Travis. Causes of delinquency. Berkeley and Los Angeles: University of California Press, 1969. LEMGRUBER, Julita. "Os números da violência". In: MENDES, Candido \& FEGHALI, Jandira. Reflexões sobre a violência urbana: (in)segurança e (des)esperanças. Rio de Janeiro: Mauad X, 2006.

LIMA, Renato Sérgio. et al. Índice de Vulnerabilidade Juvenil à Violência 2017. São Paulo: Fórum Brasileiro de Segurança Pública, 2017.

MINAYO, Maria Cecília de Souza. "A violência dramatiza causas". In: MINAYO, Maria Cecília de Souza \& SOUZA, Edinilsa Ramos de. (orgs.).Violência sob o olhar da saúde: a infrapolítica da contemporaneidade brasileira. Rio de Janeiro: Editora Fiocruz, 2003.

PROVENZA, M. M.; et al. Homicídio Doloso na Cidade do Rio de Janeiro: Uma comparação entre as bases da segurança e da saúde. Dilemas, vol. 10, n. 2, 2017.

RUSSO, Mauricio Bastos; SANTOS, José Vicente Tavares Dos. Cartografia Social dos Homicídios em Porto Alegre (2002-2006). O público e o privado. v. 15, p. 211-237, 2010.

SINHORETTO, Jacqueline; MORAIS, Danilo de Souza. Violência e racismo. novas faces de uma afinidade reiterada. Revista de Estudios Sociales, n. 64, p. 15-26, 2018.

SOARES, Glaucio Ary Dillon. Homicídios no Brasil: vários factóides em busca de uma teoria. Trabalho apresentado na Reunião da Latin American Studies Association. Miami, Flórida, 2000. Disponível em: http://lasa.international.pitt.edu/Lasa2000/Soares.PDF.

SOARES, Gláucio Ary Dillon. Não matarás: desenvolvimento, desigualdade e homicídios. Rio de Janeiro: Ed. FGV, 2008.

WAISELFISZ, J.J. Mapa da Violência 2011: Os jovens do Brasil. São Paulo/Brasília, Instituto Sangari/MJ, 2011.

Mapa da Violência 2013: Homicídios e Juventude no Brasil. Brasília, FLACSO/CEBELA, 2013.

WELZER-LANG, Daniel. A construção do masculino: dominação das mulheres e homofobia. Revista Estudos Feministas, vol. 9, no. 2, 2001, pp. 460-482. Editorial Universidade Federal de Santa Catarina.

Fórum Brasileiro de Segurança Pública. Anuário Brasileiro de Segurança Pública. 11을ição. São Paulo: Fórum Brasileiro de Segurança Pública, 2017. 
Anuário Brasileiro de Segurança Pública. 12ํ Edição. São Paulo: Fórum Brasileiro de Segurança Pública, 2018.

Trabalho enviado em 04 de fevereiro de 2019

Aceito em 02 de fevereiro de 2020 